\title{
Psychometric Properties of Stress Check List for Self and its Relationship to Health Satisfaction and Psychological Traits (Extroversion-Introversion)
}

\author{
Tomoyuki KAWADA ${ }^{1}$, Keiko $\mathrm{KATO}^{2}$ and Toshihide IIJIMA ${ }^{2}$ \\ ${ }^{1}$ Department of Public Health, Gunma University School of Medicine and ${ }^{2}$ Health Care Center at Takasaki, \\ JR Co. Ltd.
}

\begin{abstract}
Psychometric Properties of Stress Check List for Self and its Relationship to Health Satisfaction and Psychological Traits (Extroversion-Introversion): Tomoyuki KaWADA, et al. Department of Public Health, Gunma University School of Medicine-This study focused on the reliability and validity of the Stress Check List for Self (SCL-S). Relationships of the SCL-S to types of work, health satisfaction, psychological traits, current medication, and stress coping were also tentatively analyzed. A self-administered questionnaire was distributed to employees of a railroad company, of whom 1,706 men aged 18 to 55 were selected randomly and $1,045(61.3 \%)$ responded. The SCL-S consists of 30 items, each of which is scored 1 or 0 , depending on whether or not a symptom is present. The SCL-S score is defined as the summation of each binary datum. Health satisfaction is scored as 1 (satisfied), 2 (moderately satisfied), or 3 (not satisfied). The psychological trait item is scored as 1 (extrovert) or 2 (introvert). Present medication is scored as 1 (yes) or 0 (no). We also asked the respondents whether they had experienced stress coping, hobbies and consultation with others. Each of these items was scored as 1 (yes) or $O$ (no). There was a difference in the mean SCL-S value among age-groups as a whole $(p<0.05)$. Cronbach's alpha coefficient for the target group was 0.817 . Principal factor analysis was conducted on 30 items of the SCL-S. Three factors were extracted. Factor 1 consisted of three items which related to motivation. Factor 2 consisted of six items which related to physical symptoms. Factor 3 consisted of six items which related to symptoms of autonomic imbalance. These three factors explained only $18.2 \%$ of total variation. The mean SCL-S value was quite high in the groups characterized by intro-
\end{abstract}

Received June 10, 1996; Accepted Dec 26, 1996

Correspondence to: T. Kawada, Department of Public Health, Gunma University School of Medicine. 3-39-22 Showa-machi, Maebashi 371, Japan version ( $p<0.01$ ), having no one to consult ( $p<$ $0.05)$, and not having a hobby $(p<0.01)$. The higher health satisfaction score was, the lower the mean value of the SCL-S and this was significant $(p<$ 0.01 ). Multiple regression analysis was conducted to predict SCL-S scores by other variables. Significant standardized partial regression coefficient items increasing the $S C L-S$ value were introversion trait ( $p$ $<0.05)$, not having a hobby $(p<0.05)$, and health dissatisfaction $(p<0.01)$. Among these three variables, health dissatisfaction contributed most to the SCL-S. The adjusted coefficient of determination was 0.185 . These results raise the possibility that the SCL-S can be based on division into three different scales. Internal consistency was nearly acceptable with the adoption of an alpha value over 0.8 . In addition, health satisfaction was most closely related to subjectively reported stress or stress response judged by SCL-S.

(J Occup Health 1997: 39: 223-227)

Key words: Industrial workers, Stress check list, Health satisfaction, Psychological trait, Social network

The prevalence of experiencing stress among Japanese industrial workers appears to be increasing. To ascertain the recent circumstances surrounding these developments, a valid and reliable self-rating questionnaire for Japanese subjects is required. Some Japanese stress check lists have also been used $^{1,2)}$ and among them, the simple and reliable version is most useful for promoting mental health activity in the company.

Stress measurement is difficult because of the following considerations. First, psychosocial stress cannot be identified clearly. Second, personal variables relate strongly to the perception of stress. Third, psychosocial stress and the psychosomatic condition do not always change in parallel. As to 
the second point, the cause-effect relationship between stressor and stress reactions, including psychosomatic reaction or stress coping, are strongly affected by individual factors such as age, gender, personality, socioeconomic status, health status, social status and social network.

Health satisfaction is judged subjectively and is directly related to the quality of life $(\mathrm{QOL})^{3)}$. The authors focused mainly on the psychometric properties of a suitable distributed simple questionnaire developed in Japan called the Stress Check List for Self (SCL-S). Thirty SCL-S items were selected by clinical aspect or experience focused mainly on physical complaints. SCL-S was assisted by Stress Check List for Others (SCL-O), whose items were related to objective symptoms and psychological status judged by another subject. In addition, a Stress Tolerance Check List (STCL) was also prepared. Three questionnaires are permitted to be used independently, because there is difficulty in using these questionnaires simultaneously in occupational and other fields. After describing the characteristics of this questionnaire, relationships with other factors including health satisfaction and psychological traits were tentatively investigated. The authors attempted to assess the usefulness of this tool, and if it proves useful, longitudinal follow-up of workers might become possible for mental health care in the occupational field.

\section{Subjects and Methods}

Questionnaires were distributed to 1,706 employees of the East Japan Railroad Company in August of 1995. The response rate was $61.3 \%(1,045 /$ 1,706). The ages of the subjects ranged from 18 to 55 , the average being 42.4 years, and the standard deviation 8.16.

The SCL-S was devised by Katsura in 1980'). This questionnaire includes 30 binary questions which must be answered either "Yes" or "No." A "Yes" is scored 1 and "No" is scored 0. The SCL-S score is defined as the summation of each item value. Higher SCL-S scores indicate higher levels of stress (see appendix). There were explanatory sentences for each question of the original version of the SCL-S. The authors removed these additional sentences to simplify the questionnaire itself.

We also asked "To what extent are you satisfied with your health?" This health satisfaction item was scored as 1 (satisfied), 2 (moderately satisfied) or 3 (not satisfied). The psychological trait item was scored as 1 (extrovert) or 2 (introvert). Present medication was scored as 1 (yes) or 0 (no). Furthermore, having a hobby and consulting with others were each scored as 1 (yes) or 0 (no).
SCL-S scores between or among the abovementioned subgroups were compared .

The Student t-test, principal factor analysis with a varimax rotation, and multiple regression analysis (not stepwise method) were conducted. The initial igenvalue over 1.2 was set as the cutoff point, because a gap existed between the third and forth factors. Nine independent variables: age, marriage, shift work, extroversion, medication, hobby, consultation, stress coping and health satisfaction and SCL-S as a dependent variable were used for multiple regression analysis. A software program for statistical analysis, NAP $^{4)}$, was used.

As many items are included in the questionnaire, missing values existed on each analysis. There were ten missing values for age, and 696 subjects out of 1,045 were used for multiple regression analysis.

\section{Results}

Cronbach's alpha coefficient for the target group was 0.817 . There was a difference in the mean SCL-S value among age-groups by analysis of variance $(\mathrm{p}<0.05)$. Although no differences among groups were recognized by multiple comparison, a mean SCL-S value in the 30 s was the highest and the value tended to decrease with age (Table 1).

Principal factor analysis was conducted on 30 SCL-S items. Factor loading over 0.35 was tentatively selected. Three factors were extracted. Factor 1 consisted of three items which related to motivation, accounting for $6.4 \%$ of the total variation. Factor 2 consisted of six items, which related to physical complaints, accounting for $6.0 \%$ of the total variation. Factor 3 consisted of six items, which related to symptoms of autonomic imbalance, accounting for $5.7 \%$ of the total variation. These three factors explained only $18.2 \%$ of the total variation (Table 2). Cronbach's alpha coefficients for factors 1 to 3 were $0.603,0.653$ and 0.642 , respectively.

The mean SCL-S values were significantly high in the groups characterized by introversion $(\mathrm{p}<$

Table 1. Mean stress check list for self (SCL-S) values divided by age category

\begin{tabular}{rrr}
\hline Age & Number & Mean \pm SD \\
\hline $18-29$ & 56 & $4.8 \pm 4.61$ \\
$30-39$ & 354 & $5.8 \pm 4.61$ \\
$40-49$ & 377 & $5.2 \pm 4.26$ \\
$50-55$ & 248 & $4.9 \pm 3.80$ \\
Total & 1,035 & $5.3 \pm 4.31$ \\
\hline
\end{tabular}

There were significant differences in mean values among four age groups by analysis of variance $(p<0.05)$. Ryan's multiple comparison was applied, but no differences in mean values between pairs of groups could be found. 
Table 2. Varimax rotated principal factor loadings of the SCL-S

\begin{tabular}{|c|c|c|c|c|}
\hline Questions & Factor 1 & Factor 2 & Factor 3 & Communality \\
\hline Q19 & $-0.44742^{\#}$ & 0.34893 & -0.09541 & 0.33104 \\
\hline Q27 & $-0.44416^{\sharp}$ & 0.27128 & 0.03049 & 0.27181 \\
\hline Q30 & $-0.45380^{\#}$ & 0.26574 & -0.07533 & 0.28222 \\
\hline Q1 & -0.21447 & $0.46048^{\#}$ & -0.25462 & 0.32287 \\
\hline Q2 & -0.08971 & $0.36886^{\#}$ & -0.16335 & 0.17079 \\
\hline Q13 & -0.03734 & $0.38718^{\#}$ & -0.18912 & 0.18707 \\
\hline Q15 & -0.21603 & $0.52527^{\#}$ & -0.04847 & 0.32492 \\
\hline Q17 & -0.24420 & $0.45167^{\#}$ & -0.20731 & 0.30662 \\
\hline Q18 & -0.28410 & $0.37171^{\#}$ & -0.13311 & 0.23660 \\
\hline Q4 & -0.20660 & 0.20345 & $-0.45585^{\#}$ & 0.29187 \\
\hline Q5 & -0.18479 & 0.14526 & $-0.44219^{\#}$ & 0.25078 \\
\hline Q6 & -0.09361 & 0.13476 & $-0.35313^{\#}$ & 0.15162 \\
\hline Q23 & -0.14121 & 0.06690 & $-0.44015^{\sharp}$ & 0.21815 \\
\hline Q24 & -0.10163 & 0.15457 & $-0.49358^{\#}$ & 0.27784 \\
\hline Q25 & -0.17566 & 0.12130 & $-0.50237^{\sharp}$ & 0.29795 \\
\hline Q3 & -0.32473 & 0.05976 & -0.11596 & 0.12247 \\
\hline Q7 & -0.24348 & 0.04559 & -0.12298 & 0.07648 \\
\hline Q8 & -0.32673 & 0.09605 & -0.10560 & 0.12713 \\
\hline Q9 & -0.13388 & 0.15694 & -0.14793 & 0.06444 \\
\hline Q10 & -0.25109 & 0.11746 & -0.11348 & 0.08972 \\
\hline Q11 & -0.33155 & 0.18116 & -0.16315 & 0.16936 \\
\hline Q12 & -0.32097 & 0.10594 & -0.23701 & 0.17042 \\
\hline Q14 & -0.09306 & 0.29486 & -0.25157 & 0.15889 \\
\hline Q16 & -0.13729 & 0.06746 & -0.08726 & 0.03101 \\
\hline Q20 & -0.25670 & 0.26148 & -0.05424 & 0.13721 \\
\hline Q21 & -0.25165 & 0.02852 & -0.12282 & 0.07922 \\
\hline Q22 & -0.23811 & 0.05297 & -0.14785 & 0.08136 \\
\hline Q26 & -0.29030 & 0.07102 & -0.07435 & 0.09485 \\
\hline Q28 & -0.08781 & 0.05416 & -0.10217 & 0.02108 \\
\hline Q29 & -0.25371 & 0.16530 & -0.10554 & 0.10283 \\
\hline Eigenvalue & 1.92774 & 1.80192 & 1.71897 & \\
\hline$\%$ of explanation & 6.42579 & 6.00640 & 5.72990 & \\
\hline
\end{tabular}

$0.01)$, having no one to consult $(\mathrm{p}<0.05)$ and not having a hobby $(\mathrm{p}<0.01)$. The higher health satisfaction was, the lower was the mean SCL-S value, and this was significant $(\mathrm{p}<0.01)$ (Table 3 ).

Multiple regression analysis (not the stepwise method) was conducted to determine which variables correlate significantly with the SCL-S (Table 4). Variables which were significant in terms of the standardized partial regression coefficient, increasing the SCL-S value, were introversion $(0.083$, $\mathrm{p}<0.05)$, not having a hobby $(-0.081, \mathrm{p}<0.05)$ and health dissatisfaction $(0.384, p<0.01)$. The adjusted coefficient of determination was 0.185 .

\section{Discussion}

The response rate was $61.3 \%$, and systematic bias such as providing no response to stressful subjects, or vice versa, could not be assessed or was completely excluded.

Three SCL-S factors were identified, but the explanation rate was less than one fifth of the total variance. These results did not allow each factor score of the SCL-S to be used as an independent variable, and the sum total for each SCL-S item was used as a stress response, in accordance with previous research. Internal consistency, as assessed by Cronbach's alpha coefficient, was acceptable ${ }^{5}$. The authors reported the structural characteristics of the Zung Self-rating depression scale (SDS) questionnaire in Japanese workers ${ }^{6}$. The 20 SDS items were divided into three categories: the two extracted factors (positive and depressive psychological items) and the other. This residual group included somatic questions such as weight loss and 
Table 3. The mean stress check list for self (SCL-S) value divided by the existence of each personal factor and the degree of health satisfaction

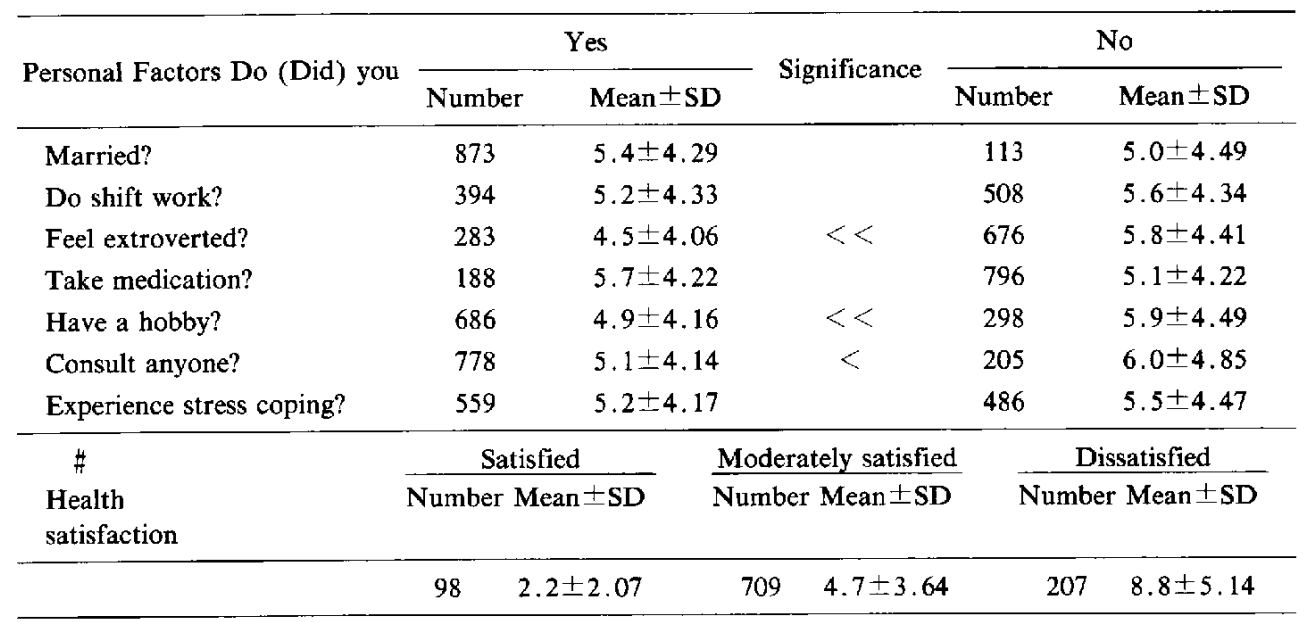

\# : Ryan's multiple comparison was applied and significant differences in the mean value between pairs of groups were found $(\mathrm{p}<0.01)<: \mathrm{p}<0.05,<<: \mathrm{p}<0.01$.

Table 4. Contribution rate of each variable to the SCL-S

\begin{tabular}{lcccc} 
& & & & \multicolumn{2}{c}{ Standardized } \\
& PRC & SE & p value & -0.073 \\
age & -0.03899833 & 0.02251686 & 0.084 & -0.077 \\
marriage & -1.061154 & 0.5527499 & 0.055 & 0.058 \\
shift work & 0.5099745 & 0.3099509 & 0.100 & 0.083 \\
extroversion & 0.7869333 & 0.3361154 & $0.020^{*}$ & 0.025 \\
medication & 0.2858610 & 0.4093705 & 0.485 & -0.081 \\
hobby & -0.7711002 & 0.3499370 & $0.028^{*}$ & -0.027 \\
consultation & -0.3041999 & 0.3912045 & 0.437 & -0.018 \\
stress coping & -0.1589722 & 0.3187731 & 0.618 & 0.384 \\
health satisfaction & 2.128377 & 0.1964706 & $<001$ &
\end{tabular}

$\mathbf{R}^{\wedge} 2: 0.44222$

DF adjusted $R^{\wedge} 2: 0.18501$

$\mathrm{R}^{\wedge} 2$; coefficient of determination ( $=$ square of multiple correlation coefficient), DF; degree of freedom, PRC; partial regression coefficient. Significance levels on multiple regression analysis using variables (not the stepwise method) are shown. ${ }^{*}: 0.01<\mathbf{p}<0.05$.

constipation. Other depression questionnaires such as the Hamilton Rating Scale for Depression, Beck Depression Inventory and The Center for Epidemiologic Studies Depression Scale (CES-D), include no somatic complains. Though there are some variations on several depressive inventories, physical symptoms cannot become main items in the questionnaire. It is also a fact that masked depression cannot be identified only by physical complaints. The authors recommend including more psychological items in SCL-S.

The stress level should be evaluated multidimensionally, and a self-rating questionnaire is the simplest method for achieving this goal. In general, each subject has his/her own desirable level of mental status, and intra-individual variation in the stress level may exist in everyday life. If stress responses are classified into physical and psychological, two-thirds of the SCL-S questions can be classified as dealing with physical stress responses. The authors recommend that psychological stress-related items should be added to SCL-S. If not, the validity as a stress check list might not be satisfactory in picking up subtle stress symptoms.

A cross-sectional study cannot identify a causeeffect relationship between job stress and health status. The relationship between stress and health satisfaction or psychological traits could, however, be clarified in this survey. Using binary data reflecting certain personal and social information, a significantly high mean SCL-S value was recognized in persons with introversion, no hobby and having 
no one to consult. Marital status, shiftwork, and present treatment had no relation to stress. The authors speculate that stress tolerance might exist or emerge with the passage of time, and the average SCL-S value would thus show no difference in terms of these factors. When stress coping was inquired about in general terms, no clear SCL-S difference was recognized, but concrete coping mechanisms such as having a hobby produced a significant difference in the mean SCL-S value. In addition, health satisfaction was significantly related to a low SCL-S score.

Furthermore, by multiple regression analysis, health dissatisfaction, the introversion trait and having no hobby were significantly associated with an increased SCL-S score. The significance level, in terms of the standardized partial regression coefficient, for health dissatisfaction exceeded those of the introversion trait and not having a hobby. The authors speculate that the cause-effect relationship of health dissatisfaction to the SCL-S is different from those of the introversion trait and not having a hobby to the SCL-S.

In this investigation, a simple and multivariable statistical analysis was used to demonstrate that health satisfaction, the extroversion trait and having a hobby appear to contribute to the resolution of stress-related problems by SCL-S, which is consisted mainly by physical symptoms.

\section{Appendix}

\section{Stress check list for self (SCL-S) questionnaire}

Have you had any of the symptoms listed below in the past month? The total number checked is defined as the SCL-S score. (Saikin ikkagetu kuraino aidani sitano yoona syoojyooga areba $\square$ ni sirusio tukete kudasai. Sono kazuno gookeiga SCL-S tokuten desu)

1. I don't feel refreshed. (Atamaga sukkiri sinai)

2. Eyes easily become tired. (Mega tukareru)

3. Occasional nasal congestion. (Tokidoki hanaga tumaru)

4. I occasionally experience dizziness (vertigo). (Memaio kanjiru kotoga aru)

5. I sometimes feel dizzy upon standing. (Tokidoki tatikurami sisooni naru)

6. I sometimes have tinnitus. (Miminariga surukotoga aru)

7. I often experience oral inflammation. (Sibasiba koonaienga dekiru)

8. Sore throat is common. (Nodoga itaku narukotoga ooi)

9. My tongue is often coated with white. (Sitaga siroku natteiru kotoga ooi)

$\square$ 10. I have recently had a decreased appetite. (Imamade sukidatta monoo soo tabetaito omowanai)
11. I occasionally experience a heavy abdominal sensation. (Tabemonoga ini motareru yoona kigasuru)

12. I have abdominal fullness or pain. (Haraga hattari itakunattari suru)

13. I have stiff shoulders. (Kataga koru)

14. I have back pain (lumbago). (Senakaya kosiga itaku narukotoga aru)

15. I do not easily recover from fatigue. (Nakanaka tukarega torenai)

16. I have lost weight. (Konogoro taijuuga hetta)

17. I easily become fatigued after events. (Nanika suruto sugu tukareru)

18. Getting up in the morning is unpleasant. (Asa kimotiyoku okirarenai kotoga aru)

19. I have poor work motivation. (Sigotoni taisite yarukiga denai)

$\square$ 20. I cannot fall asleep easily. (Netukiga warui)

21. I often dream. (Yumeo mirukotoga ooi)

22. I wake up around one or two AM. (Yonakano itiji niji koroni mega samete simau)

$\square$ 23. I experience sudden breathlessness or dyspnea. (Kyuuni ikiga kurusiku narukotoga aru)

$\square$ 24. I sometimes have palpitations. (Tokidoki dookio utu kotoga aru)

$\square$ 25. I experience chest pain. (Munega itaku narukotoga aru)

26. I catch cold easily. (Yoku kazeo hiku)

$\square$ 27. I tend to get annoyed easily. (Sukosino kotodemo haraga tatu)

$\square$ 28. My hands and feet are often cold. (Teasiga tumetaikotoga ooi)

$\square$ 29. My palms and underarms are often sweaty. (Tenohiraya wakinositani aseno deru kotoga ooi)

30. Meeting people is burdensome. (Hitoto aunoga mendooni natte iru)

\section{References}

1) Katsura T. Stress care-with oriental approach on psychosomatic aspect of disease. Seisin-Ryoho 1989; 15: 35-44 (in Japanese).

2) Nomura S, Akabayashi A, Kuboki T, Suematsu H, Yokoyama K, Araki S. Development, validation and application of a new questionnaire (stress check list: SCL- 86) for stress management in occupational health. In: Araki S, ed. Behavioral medicine: an integrated biobehavioral approach to health and illness. Amsterdam : Elsevier, 1992: 195-203.

3) Suzuki S, Aoki S, Yanai H. THI handbook. Tokyo: Shinohara Shuppan, 1989: 5-6 (in Japanese).

4) Aoki S. Igaku toukei kaiseki reference manual. Tokyo: Igaku Shoin, 1989 (in Japanese).

5) Dawson-Saunders B, Trapp RG. Basic \& clinical biostatistics. Connecticut: Appleto \& Lange, 1994: 58.

6) Kawada T, Suzuki S. Factor structure of self-rating depression scale by Zung and prevalence of depressive state of night shift workers. Jpn J Ind Health 1992; 34: 131-136. 